\title{
Ruralidad: investigación y un buen vivir alternativo
}

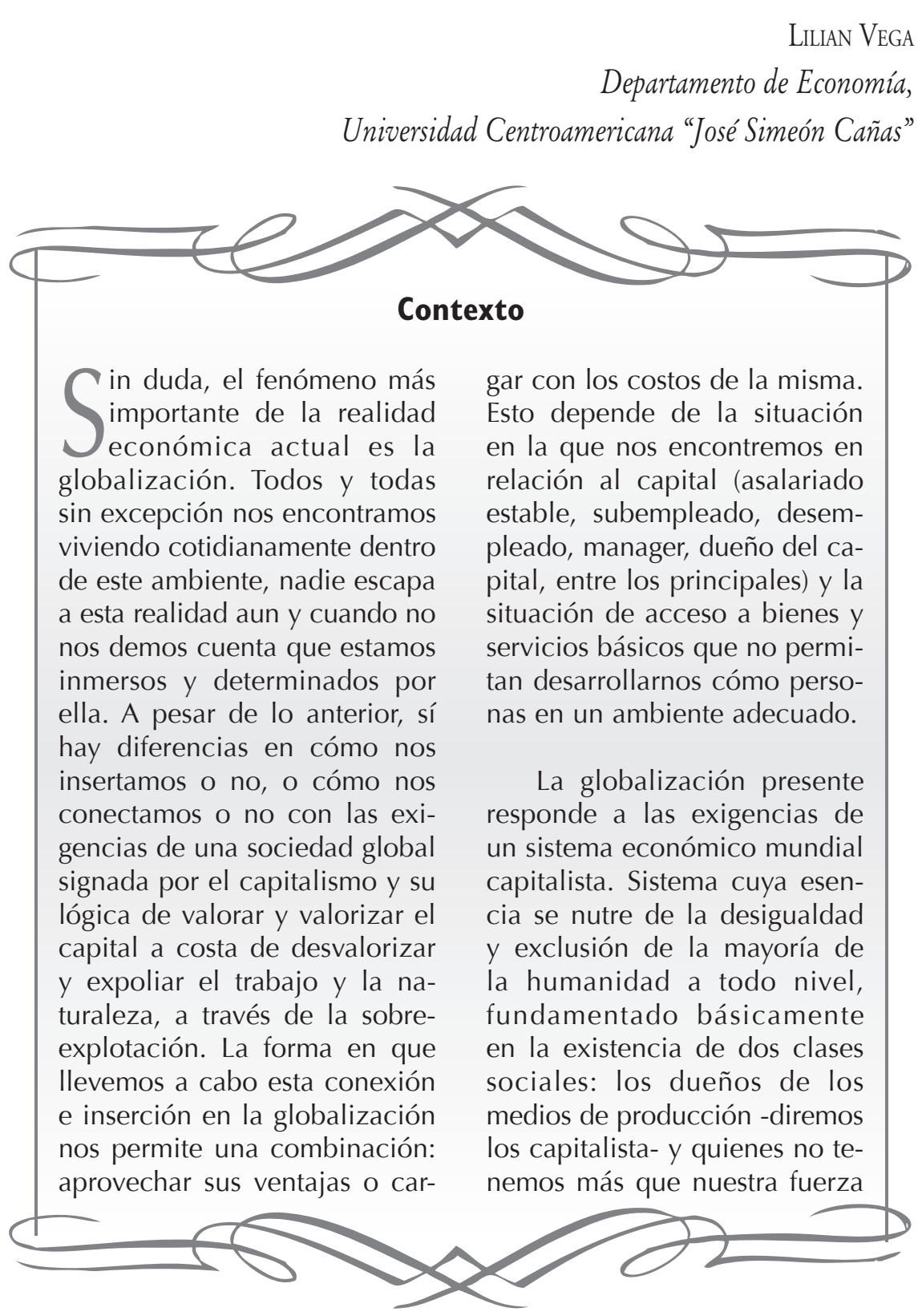


de trabajo -o capacidad de hacer y con ello crear valor- y conformamos la clase trabajadora. A esta división general que determina la forma inequitativa en que se distribuyen los frutos del trabajo, se suman otras (sub)clases sociales, por ejemplo, pequeños burgueses y gerentes, $y$ capas de desigualdad y exclusión como la de género o la de etnia. De esta manera, y en la actualidad, la sociedad global organizada ha devenido en que el $20 \%$ de la población mundial consume el $90 \%$ de los recursos mundiales, o que 3 mil millones de personas reciben el $1.2 \%$ del ingreso total del mundo mientras mil millones de personas en países ricos reciben el $80 \%$ del mismo. Este sistema distribuye el ingreso creado socialmente por millones de personas trabajadoras de tal manera que unos pocos, dueños de los medios de producción y sus clases satélites, se apropian del valor producido por una mayoría trabajadora, mientras esta mayoría de familias trabajadoras se ven cada vez más intensamente constreñidas a sobrevivir en la escases permanente de ingreso y de medios de vida.
Este sistema global, además de generar desigualdad y exclusión, genera riesgos cada vez mayores, los cuales derivan -entre otras causas- de la respuesta que la naturaleza ofrece ante las agresiones a la que es sometida en pro del crecimiento económico y el consumismo. Aunque estos riesgos los compartimos todos, la vulnerabilidad que enfrentamos difiere grandemente. De nuevo, esta mayor vulnerabilidad depende de la clase social en la que cada persona se encuentre: las millones de personas trabajadoras condenadas al desempleo o subempleo también están condenadas a vivir en condiciones precarias y de extrema vulnerabilidad, mientras las personas que se apropian de la riqueza creada suelen contar con los medios para poder protegerse de los riesgos y evitar la vulnerabilidad extrema.

Dos mundos, dos realidades partidas según la clase social a la que pertenecemos, conviviendo en un sólo planeta tierra agredido, sobreexplotado y respondiendo violentamente frente a la necesidad de perpetuar la vida, cualquiera que ésta sea, posiblemente una menos agresiva $y$ violenta que la vida humana.

\section{Planteamiento anti-sistémico}

En esta realidad global que he esbozado y de la cual sobran evidencias, se desenvuelve un ambiente académico -en el ámbito de las ciencias sociales en general y economía en particular- en el que proliferan investigaciones que se supone dan cuenta de la realidad y demuestran el sentido común académico vigente. Este sentido 
común académico da por sentado que el sistema en el que vivimos corresponde con el máximo progreso alcanzado gracias a la senda recorrida, y de lo que se trata es de encontrar formas por las cuales -sin interpelar al sistema que crea estas clases sociales con cada vez mayor diferencia en el bienestar que les es posible alcanzar entre ellas, sin denunciarlo- logren "explicar" las diferentes situaciones que enfrentan las personas según su clase social, aunque esto es sistemáticamente ignorado.

Por ejemplo, se llevan a cabo investigaciones que demuestran que la probabilidad de ser pobre de una niña que ha nacido en la zona rural es más alta que la de un niño que nace en un hospital privado del AMSS (Área Metropolitana de San Salvador), y por lo mismo se concluye que hace falta dar más oportunidades a las mujeres y en las zonas rurales del país para lograr que las probabilidades de ambos converjan a cero. Este tipo de razonamiento pasa por alto la falta estructural de creación de empleo digno -casi la única manera que tienen las familias trabajadoras de obtener ingreso y lograr acceso a las "oportunidades"- que el sistema genera. Se debe apuntar que este tipo de investigaciones corresponden con una mera demostración empírica que no entra a cuestionar las relaciones sociales (de clase, género, territoriales y demás) que dan lugar a que el sexo y el área de nacimiento sean determinantes para lograr o no un desarrollo pleno de la humanidad de la persona.

Este tipo de investigaciones incluyen entre sus mediciones de probabilidad múltiples características de los objetos (sujetos) de investigación (demográficas, territoriales, educativas, laborales de sus padres, entre otras), pero ninguna visibiliza las relaciones opresivas de poder que dan sustento a estos resultados. Se trata entonces de investigaciones que describen pero no interpelan el status quo. Investigaciones con pretensiones de neutralidad ideológica y de constatación de una realidad objetiva.

En economía, este tipo de investigaciones $-y$ otras consideradas por la élite académica a cada nivel (universidad, país, región, mundo) como de calidad- comparten la característica de contener un sesgo cuantitativo y una complejidad matemática y estadística creciente, situación que avala la cientificidad de las mismas; aunque como ya se ha apuntado, no interpelan ni tratan de comprender las estructuras sociales, privilegiando explicaciones matemáticas y estadísticas sobre los resultados, es decir sobre la apariencia.

En resumen el sistema académico validado y legitimado en el sistema capitalista global produce investigaciones consideradas científicas, cuya norma no cuestiona 
el statu quo sino que da cuenta de una realidad que parece más un reflejo de la subjetividad-social e individual- que el sistema necesita para reproducirse que un intento de mostrar un punto de vista de una realidad socio-económica, ambiental y cultural compleja, que oprime y expolia a la mayoría en beneficio de una minoría dueña de los medios de producción (y que además se mueve en el campo de la especulación). Podría decirse que se trata de investigaciones pro sistema, pero con un alto grado de cientificidad (positivista) y con pretensión de objetividad y neutralidad científica.

En este contexto, me parece importante y necesario que existan lugares de pensamiento académico anti-hegemónico que puedan ofrecer perspectivas que permitan contar con varias caras de la compleja realidad, también anti-sistémico en tanto desafía o disiente de la forma como el sistema global capitalista organiza a la sociedad, pero sobre todo cómo distribuye los frutos del trabajo.

¿Qué podría implicar una investigación con un talante antisistémico? Traigo a cuenta algunas trazas que nos pondrán en perspectiva: En primer lugar, además de describir y analizar una realidad, se trata de interpelarla desde una posición ideológica determinada, es decir dejar de lado la pretendida necesaria asepsia científica y asumir la rigurosidad académica desde la posición ideológica que dio origen a la consecución de la investigación, y que contiene las ideas fundamentales frente a la realidad de la persona investigadora; en mi caso, desde una pretensión de cambio social y a favor de los excluidos del sistema actual. En segundo lugar, crear, de alguna manera, un vínculo con procesos sociales de cambio en esta dirección; también abrir en las personas reflexiones que tengan una pretensión liberadora y que lleve a la acción colectiva con el objetivo de cambiar las estructuras sociales vigentes; es decir, la socialización de la investigación y su verdadera potencia se desarrolla dentro de los procesos sociales que buscan cambiar las estructuras sociales existentes, y no tanto dentro del mundo de la élite académica. Tercero, posiblemente dejar más lugar a la oralidad, la narrativa de la persona sujeto y no objeto de investigación, y menos a la cita directa, la referencia estandarizada y el análisis numérico del mundo académico; sin que ello implique abandonar la rigurosidad del análisis, se trata de no olvidar que la fuente del saber, en este caso, proviene de las personas sujetas de la investigación y actoras de los acontecimiento que implican cambios.

Particularmente para las ciencia(s) económica(s), privilegiar una metodología cualitativa -frente al paradigma positivista matematizado- que permita escuchar las voces vitales de los sujetos de investiga- 
ción y promueva la intervención creativa de éstos en los procesos de transformación. Por supuesto y para toda ciencia social o humana, producir un saber divergente e interpelante al hegemónico, difundirlo y promoverlo a pesar de su muy probable descalificación (académica).
Poder llevar a cabo lo anterior necesita de un ambiente universitario que se concibe como inserto en un contexto histórico que le condiciona, pero que al mismo tiempo intenta contra-condicionar y transformar con el objeto de servir más eficazmente a los intereses reales de las personas más excluidas.

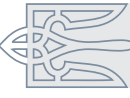

Una condición de la investigación científica válida actual es su asepsia ideológica, mientras que una investigación con pretensión anti-sistema entiende a la ideología como el desde dónde analizar. La RAE nos dice que la ideología es "el conjunto de ideas fundamentales que caracteriza el pensamiento de una persona, colectividad o época, de un movimiento cultural, religioso o político, etc.".

Para el caso particular, el fundamento ideológico se ancla en lo que nuestro ex rector y mártir denominó la civilización del trabajo como alternativa a la civilización del capital que ha llevado a esta globalización deshumanizante. A Ellacuría no le dejaron tiempo para poder profundizar o desarrollar más este concepto, sin embargo, desde mi formación y mi pertenencia al claustro del Departamento de Economía de la UCA, interpreto este concepto como antítesis al capitalismo, en tanto lo que se propone valorar y valorizar es el trabajo, y lo que equipara a un costo de producción es el capital (en todas sus manifestaciones, posiblemente de manera preponderante el capital financiero o dinero).

Si establecemos la civilización del trabajo como contrapuesta al capitalismo y la tomamos como horizonte utópico, entonces la acción, cualquiera que ésta fuera, supone la negación superadora de la civilización del capital y de su dinámica fundamental y la construcción de una nueva sociedad, local y mundial, ya no estructurada por las leyes del capital, sino que estructurada con una base humanista otorgando primacía al dinamismo del trabajo y colocándolo como la categoría dominante a la que se subordina el capital. A su vez, la superación de esta situación es uno de los mayores desafíos a la inteligencia universitaria, que debe ponerse en acto de encontrar la respuesta teórica adecuada y, además, orientar hacia la solución práctica efectiva.

Decir lo anterior es relativamente fácil, pensarlo es un tanto 
más difícil, ponerlo en acción cotidiana resulta una ardua tarea dada la realidad del capitalismo global y académico en que se desenvuelve nuestra existencia. Aquellos académicos que tengamos la pretensión de lograr llevar a cabo este tipo de investigación necesitamos al menos de lo siguiente: (i) Contar con saberes y habilidades con una doble finalidad: ser competentes "en un mundo competitivo" y al mismo tiempo ser promotores de un cambio en el sentido apuntado. (ii) Lograr conocer la sociedad para luego transformarla, no para integrarnos ya sea con conciencia o pasivamente a ella. (iii) Lograr trascender la visión vigente de empresa y empresarialdad, y construir un concepto de empresa fundado en la propiedad social-colectiva de los medios de producción. (iv) Ayudar a visibilizar los problemas estructurales de la organización económica y social y proponer activamente alternativas. (v) En el actuar universitario apuntar y, ojalá, coadyuvar a contrarrestar las tendencias hacia la concentración y centralización del capital y exclusión de las mayorías. (vi) Procurar estar cerca y acompañar procesos de transformación de las mayorías populares y excluidas, ayudándolas a que se conozcan a sí mismas, logren conciencia de clase, se valoren y actúen en consecuencia. (vii) Establecer como políticas de actuación la promoción de la equidad en toda relación.

El padre Francisco Javier Ibisate dejó a la universidad una herencia ética, humanística y académica que también nos compromete a tratar de lograr este tipo de investigación, y también a tratar de conceptualizar el desarrollo desde otro punto de vista más cercano a la valoración del trabajo y la propiedad de los medios de producción. Algunos trabajos con estos sujetos de investigación que he perfilado nos proveerán, a través de sus narrativas, pinceladas de otra realidad, totalmente otra.

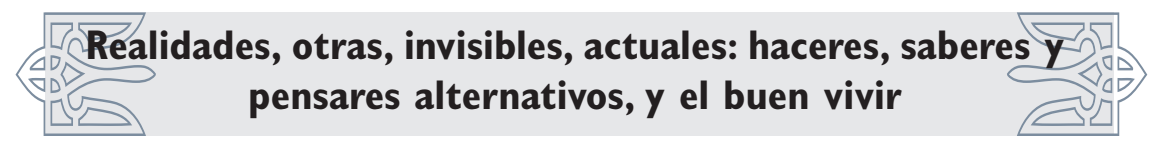

Buen vivir, más que hablar sobre lo que conceptualizaron nuestros pueblos originarios, pues conozco muy poco de su cosmogonía y pensar, quiero hablar del bienestar, o mejor dicho del bien estar; también quiero hablar sobre la importancia de la propiedad de la tierra y el trabajo agrícola para lograr un lógica contraria a la que el sistema capitalista impone a la población emigrante salvadoreña; finalmente diré algo sobre la necesidad de procesos de largo plazo para lograr cambios irreversibles o al menos difícilmente reversibles. Para ilustrar estos tres temas traeré a ustedes las palabras que expresan el pensar y sentir de personas que habitan en lo que se considera, casi 
despectivamente, zona rural en tres países de la región: Belice, El Salvador y Nicaragua.

Antes, una necesaria digresión sobre la metodología que traté de poner en práctica y que intenta estar en consonancia con lo ya expuesto. En los tres casos utilicé metodologías cuantitativas y cualitativas. La primera para tratar de imprimir la objetividad de la investigación, tratando de matizar la necesaria subjetividad presente en las investigaciones, tanto de las personas sujetas de estudio como de mí misma. Además para aportar elementos empíricos y falseables en aras de abonar a la cientificidad supuesta de las ciencias económicas dominantes. No obstante, la base de la investigación fue cualitativa.

¿Por qué una investigación predominantemente cualitativa? Principalmente porque los métodos cualitativos son los más apropiados para aquellos investigadores con una perspectiva científica e ideológica anclada en la promoción, apoyo y facilitación de procesos de transformación social que apunte a la emancipación, principalmente de personas o grupos de personas que sufren de asimetrías de poder en relación a grupos dominantes y estructuras sociales injustas que les oprimen. Asimismo, permite un crecimiento personal en ambas vías, desde los sujetos de investigación hacia la persona que investiga y viceversa. Es por esta ra- zón que se dice que el instrumento privilegiado de investigación es el o la propia investigadora.

En estas investigaciones los objetos a examinar y analizar fueron personas que perciben, sienten, piensan, sueñan; hablan seres humanos imbuidos de dignidad, y lo que dicen y saben tiene significado, sentido y valor en sí mismo. Es decir, fueron sujetos de investigación.

Mi objetivo fue tratar de lograr un conocimiento lo más íntimamente subjetivo posible para lograr la mayor profundidad en el entender, describir y analizar, a través de conceptos teóricos -construidos o en construcción. En otras palabras, tratar de captar la dinámica social que permite a estas personas el cambio social liberador de las estructuras opresoras. Al final, tratar de desarrollar conceptos que ayudarán a comprender la realidad social de las personas en su propio ambiente, y lograr responder a preguntas como: ¿Cuál es el valor de la agricultura sostenible para estas personas?, ¿cómo varía esta valoración y por qué?, ¿qué hace que estas familias se hayan desconectado de la lógica de la inserción global salvadoreña?, ¿qué es lo que permite el cambio hacia una actitud ante la vida más liberadora?

En las tres investigaciones, los aspectos conceptuales que la guiaron fueron: la contra cultura como forma de resistencia, la producción 
de bienestar y de valores de uso más que de mercancías y la economía solidaria. Cada una de ellas además se insertó en realidades complejas que viven las personas en las zonas rurales, tales como la migración, el cambio como un proceso social de largo plazo y la adopción de la agricultura sostenible como modelo tecnológico agrícola (más bien agropecuario).

\section{Desconexión de la inserción global de El Salvador Salvadoreños en Belice}

La historia de algunos de los salvadoreños en Belice, un país casi tan pequeño como El Salvador (am-

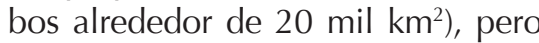
con una población similar a la que posee el departamento de La Paz (307,899 habitantes), lo que implica una densidad poblacional de 292 habitantes $/ \mathrm{km} 2$ para El Salvador y 13.4 habitantes/km2 para Belice. El Salvador posee una frontera agrícola por demás restringida y una vulnerabilidad territorial mayor al 90\%, mientras Belice posee una gran disponibilidad de recursos naturales y territorio.

A pesar que no suena como destino de la emigración de salvadoreños/as, posee flujos migratorios que en los últimos años se dirige preferencialmente a los sectores turismo, construcción, agrícola (cítricos y banano) con preponderancia masculina, a excepción del turismo y lo que se denomina cadena internacional del cuidado para mujeres. Pero durante la década de los años ochenta del siglo XX hubo otra inmigración anterior de familias salvadoreñas, que es la que me interesa mostrar.
En términos relativos para Belice, hay muchos salvadoreños viviendo en este país, 50,000 salvadoreños según los datos del MRREE; sin embargo, este dato no toma en cuenta a las personas que forman parte de las familias que llegaron durante la guerra civil y ahora poseen la nacionalidad beliceña. Es decir, cerca del 13\% de la población de Belice son hombres y mujeres salvadoreñas. Entre los asentamientos de salvadoreños más conocidos se encuentran Salvapan, San Ignacio del Cayo, San Martín, Armenia, Valle de Paz, Las Flores, Santa Marta, San Mateo y la isla San Pedro. Algunos de los mencionados son comunidades formadas por grupos de salvadoreños refugiados durante los ochenta. Para estas familias en particular la propiedad de la tierra es una reivindicación y una fuente de bienestar y arraigo.

Los rostros y gestos de los salvadoreños que llegaron en condición de refugiados durante los años ochenta del siglo XX hablan enfáticamente sobre lo vital de la propiedad de la tierra para sentirse realizados como personas. Para ellos, 
llegar a Belice significó cumplir el anhelo de siempre, el propio y el de sus ancestros: poseer tierra para cultivar y para vivir de lo cultivado, campesinos de pura cepa que construyen bienestar y felicidad a través del trabajo con la tierra. Tuvieron que seguir un proceso formal: primero, registrarse como refugiados y aceptar las condiciones que ofrecía
ACNUR, luego iniciar el proceso de asentamiento, posteriormente la residencia, finalmente lograr la ciudadanía, la reunificación de su familia y la propiedad de la tierra. Todos estos logros conseguidos con trabajo los arraigan a Belice con la más fuerte de las cadenas, la de la felicidad y el bienestar:

... la gente está acostumbrada porque tenemos tierra para trabajar, y la persona que tiene documentos tiene más probabilidades de tener su propia tierra, pero tiene que luchar, y trabajar, porque aquí todo va por medio de un proceso, reglamento, leyes y hay que hacerlo legalmente porque si uno hace ilegal las cosas de ahí vienen las consecuencias (salvadoreño residente en Las Flores).

Basta con recorrer someramente nuestra historia patria, marcada por el conflicto por la propiedad y uso de la tierra, para entender el sentimiento de nuestros compatriotas campesinos en Belice.

La situación de los salvadoreños que Ilegaron a Belice en los años ochenta es de realización personal y familiar. Llegaron como refugiados protegidos por ACNUR, huyendo de un país en guerra en dónde la ma- yoría de ellos jamás fueron propietarios de tierras agrícolas, llegaron a un país que se estaba estrenando como país libre e independiente. ${ }^{1}$ Belice acogió a 7 mil refugiados salvadoreños y junto con ACNUR llevaron a cabo un programa habitacional y de entrega de tierras y de legalización de la residencia permanente, para así formar una comunidad de salvadoreños en Belice, a quienes les cambió la vida:

No había caminos, solo veredas. Empezamos a hacer ranchitos de guano, a los 3 - 4 años Naciones Unidas inició a medir áreas para casa y parcelas de trabajo. No había agua ni energía eléctrica. El 83 inició el proyecto. [...] al principio 30 familias salvadoreñas en la primera etapa. Valle de Paz es bonito ahora, casi abastecemos a Belice de agricultura (Roberto Aníbal Batres, salvadoreño entrevistado en Santa Rita).

Yo fui el primerito aquí, no había gran cosa, nadie, no había ni un alma en este lugar, yo fui el primero que vine aquí a 
hacer una casita, aquí estaba la niña Ruth que aquí daba la comida, solo había un menonita con la casita (Marcelino Echeverría, salvadoreño nacido en Cabañas residente de valle de Paz).

Los salvadoreños que llegaron a principios de los ochenta como refugiados ahora son dueños de parcelas en las que producen para autoconsumo y para abastecer a Belice de frutas, verduras y hortalizas. Además, sus hijos y sus nietos tienen la oportunidad de estudiar sin diferencias en la calidad educativa que reciben en relación al resto de la población beliceña. En Belice han logrado el sueño de ellos y de sus antepasados, razón suficiente para quedarse a vivir aquí y recordar a El Salvador como el terruño que los vio nacer, crecer, sufrir y finalmente huir, a la tierra que resultó ser la prometida, Belice.

Aunque para aquellos salvadoreños que creen en el "sueño americano", vivir en una zona rural, trabajar de agricultor, desarrollarse en una sociedad tranquila sin sobresaltos y con poco acceso a mercados tecnológicos no es considerado como exitoso, esta situación sí representa un éxito y la consecución de un anhelo de vida para los salvadoreños que llegaron como refugiados y que ahora son dueños de su tierra y de su trabajo, poseen vivienda digna y sus hijos tienen oportunidades reales de mejorar su nivel educativo y estatus social, pues viven en una comunidad tranquila en la que se disfruta el tiempo de trabajo, de ocio, de familia y de espiritualidad.

El arraigo que lograron en Belice lo aleja del modelo de integración del país con el mundo en la era de la globalización. ¿A qué me refiero? A que los salvadoreños que llegaron como refugiados y que luego lograron además de tierra, la calidad de ciudadanos y la reunificación de sus familias, no envían remesas a El Salvador, y su arraigo con el país es de nostalgia. Esta comunidad de salvadoreños, la más antigua en Belice, parecen estar fuera del modelo de integración global que El Salvador ha consolidado y en el cual el envío de remesas es parte de la lógica migratoria familiar y de país.

Es así como la propiedad de la tierra y la propiedad de los frutos del trabajo permite a estas familias campesinas salvadoreño/beliceñas hacerse de los medios de vida suficientes para lograr una vida digna y con bienestar, como nos lo resume Elí: "pero los agricultores ganan y viven bien, están mejor los que tienen sus propios negocios, algunos agricultores venden su cosecha los martes y viernes. Hombres y mujeres, pero para vender las parejas" (Elí Sánchez Pérez). 
Esto es buena noticia; a pesar del avance neoliberal y globalizador, no todo se puede comprar con el dinero, por ejemplo la paz de un atardecer sentado en el pórtico de la casa o una caminata agarrados de la mano con la persona que se ama cerca de la medianoche o la tranquilidad de saber que los hijos quedan jugando fuera con sus bicicletas mientras se está fuera de casa, y que se tiene la certeza que al volver ellos estarán sanos y salvos. Estos son algunos de los ámbitos de la vida que salvadoreños viviendo en Belice perciben con un mayor bienestar.

La reflexión que me surge al encontrarme con esta realidad migratoria, y con esta racionalidad productiva y reproductiva, es que es posible lograr que las familias campesinas sean productivas $y$ produzcan valores de uso -en este caso productos agrícolas quizá agropecuarios- que proporcionan alimentos y bienestar para ellos y la comunidad en la que viven. Se necesita propiedad de la tierra, acompañamiento inicial y condiciones de comercialización adecuadas. En Belice las condiciones son más favorables que en El Salvador, pero políticas gubernamentales (nacional, municipal o ambas) que fomenten la comercialización asociativa, por poner un ejemplo, podría coadyuvar a que surgieran emprendimientos productivos con lógicas que valoren más el trabajo, sobre todo uno tan importante como el involucrado en la producción de alimentos, y mejoren las condiciones de bienestar en ambos lados de la transacciones.

\section{La agricultura sostenible}

La agricultura sostenible es una opción tecnológica que contribuye a lograr una racionalidad económica sostenible y solidaria, lo que también favorece lograr mejorar en el bienestar material y espiritual de las personas que la practican y sus familias, al mismo tiempo que coadyuva a lograr una racionalidad económica más solidaria y menos (neo)liberal.

Dejemos hablar a algunos campesinos que practican la agricultura sostenible en sus parcelas, ninguna de las cuales pasa de 3 manzanas. ${ }^{2}$ Algunas personas sujetas de mi investigación me mostraron parte de su conciencia crítica y la comprensión sobre cómo la agricultura química genera una espiral viciosa de degradación ambiental y depredación del suelo, lo que a su vez exige mayor utilización de químicos y mayor necesidad de "inversión" inicial e implica (en la sociedad capitalista en la que vivimos) pérdida de bienestar y capacidad de sostenibilidad y también mayor vulnerabilidad. Por otra parte, las personas que ponen en práctica la agricultura sostenible se relacionan con la tierra como un ser vivo, como parte de la vida que se reproduce: 
Las tierras se van debilitando; si no es con el químico, no dan, se ve a simple vista (Alonso).

Para ellos, la agricultura sostenible es mucho más que sólo una tecnología de producción amigable con el medioambiente, pues mejora la relación con la naturaleza y la tierra en particular, es una manera nueva de relacionarse con la tierra asimilándose inmerso en un sistema que logra una mejor reproducción y calidad de vida. El punto más importante no es tanto lograr ahorrar dinero e insumos, sino lograr una forma de vivir diferente que pone al centro el bienestar de todos, incluyendo aspectos como la nutrición, la salud física y mental, la alegría de vivir y el ecosistema:

Es una forma de vivir diferente, porque es una agricultura que sí le ayuda a uno a mejorar la salud, se alarga más la vida de uno" (Juan José).

...por el mejoramiento que ha tenido la persona en su trabajo [...] Es una alternativa para cambiar nuestra vida $y$ para lograr nuestra soberanía alimentaria, seguridad alimentaria tenerla segura y más sana, porque nosotros la cultivamos y sabemos que le aplicamos (Rosa Idalia).

Esta nueva forma de relacionarse con la tierra y la naturaleza genera un círculo virtuoso de productividad, pues a medida que se consolida la práctica agrícola sostenible, la producción y diversificación de la misma es cada vez más halagüeña:

Yo les digo aquí en Los Almendros, que si todos sembraran como yo [es decir, utilizando la agricultura sostenible], humm... en esta tierra estéril [en referencia a como califican el tipo de tierra en el cual él y su familia practican la agricultura sostenible] yo cosecho: papaya, güisquil, ayote, granadilla, arroz, maíz, frijol, tomate (Juan José).

... porque en agricultura sostenible se cree que cada año se va mejorando la parcela, se ha visto porque si yo usara sólo químico no naciera fácil, por ejemplo, aquí no hace falta sembrar el chipilín ni la mora, al primer aguacero ellos nacen solitos porque no se ocupan químicos (Rosa Idalia). 
En El Salvador rural, la concentración de tierras y la carencia de ellas ha sido y es una característica estructural; en este contexto, una característica de primer orden de la agricultura sostenible es que funciona para micro parcelas, así la práctica de la agricultura sostenible permite lograr producciones de vegetales diversas y adecuadas para sostener la nutrición de una familia:

Pero en una tarea ${ }^{3}$ alguien que sabe pensar, en una tarea tiene un montón de hortaliza y de ahí está sacando sus ingresos también, y no es menester una gran extensión, con este poquito tiene de toda siembra, como una cuarto de tarea basta (Alonso).

La práctica de la agricultura sostenible para Rosa Idalia, Juan José, Alonso Rodrigo, Erasmo y Rosa Aminta ha significado desaprender lo que la sociedad capitalista le ha enseñado a lo largo de su vida, sobre lo qué es el ser y el hacer de los campesinos. Sus palabras evidencian, al menos, un camino emprendido de deconstrucción que les ha permitido encontrar en la práctica de la agricultura sostenible una forma de enfrentar la falta de ingreso y de suelo agrícola.
Debido a que el individualismo es fundamental para que el sistema funcione y se desarrolle, éste está muy arraigado en la conciencia de la mayoría de las personas; es por esto que la sabiduría de las personas, quienes además practican la agricultura sostenible, las Ileva a reflexionar sobre la necesidad de insistir en el tema en capacitaciones o jornadas de reflexión, así como en la necesidad del trabajo colectivo y organizado, y el efecto que tiene el logro de resultados positivos para lograr el cambio de actitud:

No le sabría decir si funcionaría, hay que capacitar a esta gente darles una charla. Fíjese que aquí no le hayo eso, aquí la gente es dura. [...] La gente no está educada en esa parte, yo creo que se puede hacer un intento otra vez, pero se tendría que mover a esta gente a la cooperativa para hacerles una nueva invitación (Rosa Aminta).

Si se organiza toda la gente del país hay soluciones, porque organizada tiene cómo hablar y ser escuchado. [...] Hasta ahorita no se puede hacer esto, sino que tiene que esperarse para ver si va a ver un impacto más fuerte, entonces sí tiene que organizarse la gente (Alonso). 
Otro tema importante, en tanto coadyuva a lograr una actitud liberadora, es la capacidad de comprender que los deseos inducidos por el sistema en muchos casos no son más que eso, deseos hacia mercancías que en realidad no son necesarias para reproducir la vida o producir bienestar, por ejemplo:

\begin{abstract}
Con el celular y nuevas tecnologías ha sucedido como cuando vinieron los españoles, que por un espejo entregan oro; ahora es igual, lo mismo ha sucedido, porque ahora somos peores [...] Totalmente eso de gaseosa, Campero es estar comiendo un bagazo, digamos comer sólo el químico, esos pollos cheles de granja crecen sólo a químico, y para uno es dañino, al tiempo vienen resultando enfermedades que uno ni cree (Alonso).
\end{abstract}

La actitud emancipadora lleva consigo la revalorización de uno mismo tanto material como espiritualmente, en beneficio propio y de los demás. La conciencia sobre el valor que poseemos como ser humano es un paso importante en este proceso de liberación, es un proceso que implica cambiar el pensamiento, la actitud y la acción; una actitud de apertura y compro- miso con el otro y de resistencia razonada contra el sistema que posee múltiples formas de opresión. Nuestros sujetos de investigación expresan muy bien esta idea de proceso continuo de permanente reflexión con otros, de actitud crítica frente a las ideas hegemónicas y de acción verdaderamente revolucionaria, porque nace de la conciencia interior:

Hablamos de metodología de cambiar el pensamiento de las personas [...] Es metodología de pensar, cambiar pensamiento, por ejemplo, metodología de campesino a campesino, no como la de las telefónicas porque eso sí es política. Nosotros ya no nos reflejamos como líderes sino como animadores que ayuden a las personas a cambiar su pensamiento (Rosa Idalia).

Los gobiernos le han apostado al sistema capitalista, a nuevos modelos, y nosotros no necesitamos nuevos modelos, porque hay suficiente recurso humano y conocimiento de los viejos con los que podemos salir adelante, porque los nuevos modelos solo nos han traído más pobreza, pobreza de lástima pues (Juan José). 
También reconocen la necesidad de ser ejemplo multiplicador en nuestro entorno, pues el verdadero cambio social necesita de multitudes convencidas, y este convencimiento surge del trabajo diario, y de nuevo la conciencia sobre lo valioso del aporte personal logra consolidar la persona que se revela activamente y pacíficamente contra el sistema, aunque también reconoce derechos exigibles ante el Estado:

Yo pongo mi grano de arena desde el momento que le estoy enseñando a mis hijas, hijos, yernos, nueras estoy contribuyendo a dar empleo y disminuir la delincuencia; me falta pedir y exigir (Juan José).

En resumen, nuestros sujetos de investigación revalidan la necesidad de una permanente reflexión crítica sobre la realidad, dentro de la cual puntos medulares son lo que tienen que ver con calidad superior del trabajo y la búsqueda de soluciones cooperativas, organizadas y solidarias frente a las soluciones individualistas y centradas en el bienestar individual. Por otro lado, también confirman que la actitud de liberación es un proceso, que al igual que la agricultura sostenible, posee varios flancos de acción; pero avances en uno de ellos colaboran a que avances en los otros sean más expeditos, y así poco a poco se consolide el cambio.

\section{Malpaisillo: los procesos son de largo plazo y la reflexión}

Malpaisillo es la cabecera municipal de Larreynaga, departamento de León. Se encuentra en una zona de riesgos volcánicos y sísmicos; además, el municipio es susceptible al fenómeno de "El Niño" y de "La Niña", lo que significa que está sujeto frecuentemente a sufrir periodos de sequías e inundaciones. Las principales actividades económicas de la zona fueron el cultivo de algodón y la explotación minera, ambas abandonadas cuando dejaron de ser rentables.

En este lugar se estableció una ONG Ilamada Xochilt Acatl, fundada el 13 de octubre de 1991, en medio de una realidad marcada por el desempleo producto de la crisis del algodón y del Estado, una producción agropecuaria familiar escasa, una masiva emigración principalmente de hombres hacia Managua o hacia el exterior buscando empleo, una desarticulación de las pocas cooperativas establecidas durante los primeros años de la Revolución Sandinista, y en general un panorama de desesperanza. A principios de los años noventa del siglo $X X$, se configuró una situación de crisis que se convirtió en una hambruna que llevó a la desnutrición 
y muerte a porcentaje significativo de la población, sobre todo infantil.

En este contexto, las primeras intervenciones de Xochilt Acatl buscaban sobre todo superar la masiva desnutrición infantil y la generación de ingreso. No obstante, rápidamente se genera conciencia sobre la necesidad de apoyar lo que ahora se conoce como autonomía económica, al mismo tiempo de profundizar la concientización y reflexión colectiva. Entre los proyectos llevados a cabo desde 1993 a 2011 sobresalen: huertos y frutales, cabras y ovejas, pozos que incluyó una pila pequeña para facilitar el manejo y una bomba de mecate, reforestación de patios para crear microclimas, siembra de frutales, producción de insumos para la agricultura orgánica, apoyo con maquinaria, herramientas, asistencia técnica agrícola y veterinaria, crédito en especies y acceso a tierra.
Desde el inicio se utilizó tecnología amigable con el medio ambiente. A lo largo del tiempo, han logrado contar con una propiedad colectiva de medios de producción como establos, infraestructura productiva, emprendimiento productivos colectivos como centros de acopio y tiendas comunitarias. A lo largo de los años de trabajo, se han logrado procesos para contar con educación básica y técnica, así como también educación de género y reflexión permanente, trabajo organizativo y cooperativo.

Para las mujeres campesinas de Malpaisillo los procesos de reflexión son valiosos, lo mismo que el crecimiento personal que lleva aparejado y la conciencia sobre sí mismas y la valía personal. Cuando se les pregunta sobre qué es lo que más les ha gustado del trabajo con Xochilt Acatl y el proceso que han seguido, responden:

El crecimiento personal, conocerme, saber de mis valores y mis derechos, poder tomar mis propias decisiones.

No pido permiso, comparto la decisión.

Antes tenía temor de expresar, me fui dando cuenta de mis derechos como mujer.

... lo que más me gusta de la Xochilt son los talleres y las reuniones, me hacen pensar $y$ cambiar.

Este trabajo de reflexión con las mujeres, además de lograr establecer mejores bases para una autonomía, les permite a ellas auto valorarse, mejorar la percepción sobre sí mismas y actuar en consecuencia frente a ellas mismas y frente al resto de personas con quienes se relacionan. 
Algunas instituciones incluyen, al elaborar sus proyectos, actividades de reflexión en temas relacionados con el género o con el sistema económico hegemónico, ambos sitios de opresión y subordinación para las personas. Sin embargo, cuando esta reflexión es más bien esporádica y no continúa ni permanece en el tiempo, no se logran los cambios internos en las personas como para lograr un cambio de actitud ante la vida y en la forma como lleva las diferentes relaciones sociales. Este trabajo de reflexión permanente de Xochilt Acatl en Malpaisillo tiene ya décadas.

Como seres humanos que somos, lo más difícil no es poner en práctica nuevas tecnologías productivas o nuevas formas de hacer las cosas, sino cambiar nuestras actitudes, percepciones sobre la realidad que nos toca vivir y nuestras valoraciones críticas a la misma. Para lograr cambios a nivel interior de las personas, se necesita que el tiempo pase y la reflexión sea permanente. La reflexión permanente es una clave del cambio en las mujeres. Ellas también perciben; por ejemplo tiene clara conciencia del empoderamiento y autonomía económica que han logrado o están en proceso de lograr. A continuación algunas respuestas obtenidas de los grupos focales ante la pregunta, ¿qué es lo que creen que ha cambiado en sus vidas al vincularse con Xochilt Acatl?:

Mayor conocimiento propio: derechos, cómo defendernos cuando nos están maltratando, saber decidir.

Mayor conocimiento y capacitación: como trabajar lo orgánico.

Estar organizadas: nos permite tenernos confianza, solidaridad, y amistad.

Demostrar que podemos hacer cosas como sembrar y cosechar.

Estas mujeres también son conscientes de la importancia de la cooperación y trabajo colectivo para lograr mejorar el bienestar de la comunidad, sus familias y las personas. Esta conciencia de bienestar incluye, además del acceso efectivo a los bienes y servicios para reproducir la vida material y espiritual (incluye tiempo para la espirituali- dad, el esparcimiento y la familia), lo que suele Ilamarse gobernanza; o cómo se llevan a cabo las decisiones que afectan la vida, también la necesidad de cambiar la cultura de la sociedad y que las nuevas generaciones crezcan con nuevos valores y actitudes. Las respuestas siguientes evidencian lo comentado: 
Hay más ingreso en las comunidades.

Capacitación de actores y actores, entonces mayor participación ciudadana y esto permite el desarrollo.

Transmitimos nuestras ideas a nuestros hijos.

Producimos y vendemos más barato y con más calidad: más sano y mejor.

Hay menos pobreza y desnutrición que antes, comemos mejor. Sobre todo con la leche de cabra hemos controlado la anemia en los niños y ancianos.

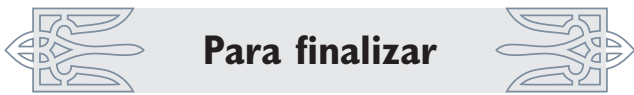

La economía es mucho más que los números y las finanzas, y como decía mi querido padre Ibisate "no hay que olvidar que detrás de los números y los indicadores económicos lo que hay son personas". Hay formas de investigación económica que intentan rescatar aspectos esenciales de la humanidad de las personas y de los entornos sociales que difícilmente se pueden expresar numéricamente sin perder esencialidad. Se trata de un tipo de investigación alejada de la legitimada por la academia economista (ieconomicista?) y posiblemente sujeta de descalificación. También tenemos realidades que no responden a la lógica de la hegemonía capitalista vigente, existen grietas por las cuales se cuelan realidades y racionalidades que apuntan a lo anti-sistémico, que muestran posibilidades de cambio que puede amenazar la aparente solidez del sistema capitalista que oprime a la mayoría.
La universidad es un lugar privilegiado, sobre todo la UCA, en dónde existe una tradición de investigación y acercamiento a la realidad histórica, para desde allí tratar de influir en cambiarla. En estas Jornadas de Reflexión Económica Francisco Javier Ibisate "Desarrollo rural: presente y futuro de las Naciones", he presentado una alternativa para llevar a cabo investigación participativa, es decir, Ilevarla a cabo junto a los sujetos de investigación, quienes a su vez están llevando a cabo proceso de transformación interior y de su entorno en aras de construir una realidad con mayores posibilidades de realización y bienestar.

Desde mi punto de vista, ambos planteamientos -la forma de investigar y las acciones concretas que llevan a cabo estas personas con quienes hemos construido conocimiento- tienen de manera 
intrínseca una vertiente anti sistémica, al mismo tiempo constituyen pequeños espacios de liberación o de emancipación del status quo social y académico, éste que al imponérsenos nos oprime.

\section{Referencias bibliográficas}

os Ellacuría, Ignacio (1975). "Diez años después, ¿es posible una universidad distinta?" Discurso pronunciado con motivo del décimo aniversario de la Universidad Centroamericana "José Simeón Cañas". Septiembre de 1975, en Planteamiento universitario 1989. UCA, San Salvador, El Salvador, C.A. Febrero, 1989.

os Ellacuría, Ignacio (1985). "Los retos del país a la UCA en su vigésimo aniversario". Discurso pronunciado con motivo del vigésimo aniversario de la Universidad Centroamericana "José Simeón Cañas." Septiembre de 1985, en Planteamiento universitario 1989. UCA, San Salvador, El Salvador, C.A. Febrero, 1989.

os Gutiérrez, Eduardo. "¿Hallaremos el radicalismo no riguroso? Imágenes y rastros sobre el pensamiento crítico latinoamericano en comunicación", en Chasqui (13901079), junio 2012, Fascículo 118.

os Morales Domínguez, Esteban. "La Economía Política Marxista. Retos del tercer milenio". Centro de Estudios sobre Estados Unidos, Universidad de La Habana (CESEU-UH). La Habana, Cuba. Junio 2000. Disponible en: http://www.uh.cu/centros/ceseu/BT\%20-\%20Economia\%20norteamericana/IEM14.pdf

os Samour, Héctor. "La universidad latinoamericana frente a la civilización del capital", en Las universidades de América Latina en la construcción de una globalización alternativa. Coordinación: María Eugenia Sánchez. Embajada de Francia/Universidad Iberoamericana Puebla/Universidad Iberoamericana León/Instituto Tecnológico y de Estudios Superiores de Occidente.

os Sánchez, Javier. "¿La universidad como problema ante una globalización alternativa?, en Las universidades de América Latina en la construcción de una globalización alternativa. Coordinación: María Eugenia Sánchez. Embajada de Francia/Universidad Iberoamericana Puebla/Universidad Iberoamericana León/Instituto Tecnológico y de Estudios Superiores de Occidente.

os Tünnermann, Carlos. "¿Qué tipo de universidad es pertinente para la construcción de una globalización alternativa desde América Latina?", en Las universidades de América Latina en la construcción de una globalización alternativa. Coordinación: María Eugenia Sánchez. Embajada de 
Francia/Universidad Iberoamericana Puebla/Universidad Iberoamericana León/Instituto Tecnológico y de Estudios Superiores de Occidente.

os Vega, Lilian. "La Proyección Social Universitaria en la realidad actual". Presentación en Power Point a propósito del seminario interno de la Universidad Centroamérica "José Simeón Cañas". "Proyección Social: Concepto, realidad, indicadores y retos". Febrero de 2007.

os Vega, Lilian. "¿Por qué hablar de exclusión y no de pobreza?". Contrapunto, periódico digital. 27 de abril de 2009. Disponible en: http://www. archivocp.contrapunto.com.sv/coyuntura/por-que-hablar-de-exclusion-yno-de-pobreza

os Vega, Lilian. Agricultura sostenible: reflexiones para el bienestar y la transformación social. Fundación Jesuita para el Desarrollo (SJD). Antiguo Cuscatlán, agosto de 2011.

os Vega Lilian. Sistematización del proceso: área económica de Xochilt Acatl, una búsqueda práctica del desarrollo desde el empoderamiento y autonomía económica. Xochilt Acatl. Malpaisillo, Larreinaga, Nicaragua, octubre de 2011.

os Vega, Lilian. "Salvadoreños en Belice", en Estudios Centroamericanos, ECA. Octubre-Diciembre de 2012. Volumen 67, número 731, pp. 539564.

Notas

1 Belice logro su independencia en 1981, año en que también fue decretada la Constitución que la rige.

2 Esto corresponde a 2.1 hectáreas $(1 \mathrm{mz}$ $=0.7050 \mathrm{ha})$.

3 Una tarea es una medida de superficie que varía según la zona del país en el que se utilice, su rango oscila entre 8 y 16 brazadas (ambos brazos extendidos) de hombre por lado de un cuadrado. 